\title{
Comentário IV
}

\author{
Margareth Rago \\ Departamento de História, IFCH/ Unicamp
}

Os lugares do corpo

O rico e minucioso levantamento dos estudos históricos sobre o corpo, realizado por Mary Del Priore, descreve um amplo leque temático nas narrałivas das experiências corporais. Nos limites deste comentário, gostaria de ater-me a um campo específico de problematizações, sugerido pelo texto: o que discute a maneira pela qual o corpo tem sido pensado pela produção acadêmica e pergunta pelas dimensões teóricas e políticas de sua incorporação pela historiografia. Algumas das minhas observações retomam pontos levantados no estudo de Mary Del Priore, em especial sua preocupação em demarcar os inícios de uma história do corpo e as formas de inserção da temática no campo historiográfico; outras visam apontar para certas ausências, que nos causam alguma perplexidade, em se considerando a proposta de um dossiê sobre a História do Corpo.

Sugiro, para tanto, que consideremos as principais portas de entrada da discussão sobre o corpo na historiografia internacional e brasileira. Três pontos ou lugares me parecem, então, fundamentais para se pensar a emergência do corpo na História: o primeiro remete às ressonâncias do pensamento de Michel Foucault na produção historiográlica e na renovação dos estudos históricos, a partir da retomada da Escola dos Annales e do boom da Nova História, entre as décadas de 70, 80 e 90; o segundo refere-se ao impacto do feminismo, em seus diferentes momentos e movimentos, sobre a produção acadêmica, também a partir destas últimas décadas; e o terceiro é relativo às pressões e reivindicações sexuais, 
1. Veja-se a respeito James A. Henretta (1979). sociais e políiticas lançadas pelos movimentos homossexuais masculino e feminino.

Foucault e a História do Corpo

Considerando as três últimas décadas, não há como negar a projeção readquirida pela Escola dos Annales, assim como pela Nova História, num momento de esgotamento do marxismo enquanto forma de pensamento privilegiada na construção das explicações históricas. Basicamente a partir dos anos 1970, emergem no campo historiográfico temas relativos ao corpo e à sexualidade, ao mesmo tempo em que novos agentes sociais, os "excluídos da História", irrompem nas páginas das teses e livros acadêmicos, reivindicando total visibilidade.

A emergência dos novos objetos e sujeitos nas pesquisas e estudos históricos evidenciou, desde logo, a estreiteza e a insuficiência dos conceitos trazidos do campo marxista para se construir possiveis interpretações dos fenômenos observados e a necessidade de novas categorias analíticas mais adequadas e sofisticadas. Por mais que muitos dos novos temas trazidos pela Nova História, desde a tradição dos Annales - como aqueles que dizem respeito à história das mentalidades e das sensibilidades, dos sentimentos, dos instintos, do amor e da sexualidade, do medo, das paixões, do pudor, da vida e da morte -, tenham sido posteriormente trabalhados em solo marxista, não há dúvida de que evidenciaram as limitaçōes decorrentes da forma de análise adotada. Há que se lembrar, ainda, que nem a Escola dos Annales nem a Nova História se caracterizaram enquanto uma historiografia marxista, por mais que se encontrem historiadores de filiação marxista entre seus pares. Lembremos que a maioria dos historiadores franceses ligados ao grupo tem revelado uma grande abertura ou, se se preferir, ecletismo teórico, permitindo-se combinar conceitos marxistas com outros provenientes do pós-estruturalismo, a exemplo dos foucaultianos. Alain Corbin (7987), por exemplo, em Saberes e odores, trabalha a difusão da sensibilidade olfativa da burguesia em ascensão, na França, desde o final do século XVIII, incorporando os conceitos foucaultianos de poder disciplinar e de práticas discursivas, ao lado de uma análise da luta das classes e das resistências sociais.

Enfim, nos momentos "de alta" das interpretações marxistas na historiografia, os temas relativos do corpo, aos instintos, às emoções foram esquecidos ou secundarizados como "perfumarias", frente às questões privilegiadas por uma hisłoriografia volłada para a temática da Revolução e da luta de classes?. Preocupados com o conhecimento da "realidade objetiva", fundamental para se detectar os rumos da Revolução, assim como com os setores sociais considerados "portadores do universal", os historiadores procuravam encontrar os sinais da luta revolucionária na cidade e no campo, atentos às suas manifesłações e expressões políticas. A Escola dos Annales dava, nesse sentido, respostas pouco atraentes. Afinal, sabemos o quanto os historiadores ligados ao grupo, tanto quanto à Nova História, foram e são mais atentos à busca das continuidades e permanências na "longa duração" do que às transformações sociais que levariam à passagem do "reino da necessidade" para o prometido "reino da liberdade".

Proponho, portanto, levarmos em consideração, nesta discussão, os lugares por onde o corpo passa a ser incorporado enquanto dimensão fundamental para o conhecimento histórico. E, neste ponto, o levantamento de Mary Del Priore 
revela uma grande ausência: refiro-me a Michel Foucault que, em 1976, publicava - primeiro do que pretendia que fossem os vários volumes da História da sexualidade. A crítica que detonava em relação às nossas habituais formas de pensar e de produzir o conhecimento, tanto quanto o elogio que dedicara à Escola dos Annales, na Arqueologia do saber, deixava claro que falava de um outro lugar, bastante difícil e confuso para os historiadores formados tanto na tradição marxista, quanto na positivista. Ora, desde sempre o marxismo esqueceu - corpo, privilegiando a dominação ideológica sobre a alma, a consciência, o espírito dos indivíduos e grupos sociais. Foucault veio chamar a atenção dos historiadores para a existência do corpo enquanto dimensão política historicizável e fundamental para que repensássemos os conceitos de poder, de verdade, de ciência, com os quais operávamos e para que entendêssemos as sofisticadas e invisíveis tecnologias da dominação burguesa. Apontou, pois, para o corpo como lugar de investimento dos dispositivos estratégicos do poder, das práticas disciplinarizantes, tanto quanto das práticas discursivas que o instituíam a partir de referências médicas, jurídicas, criminológicas e religiosas (cf. Foucault 1977 e Rago 1995). É interessante ver como ele-mesmo anuncia a inovação que opera na produção do conhecimento histórico:

"Os historiadores vêm abordando a história do corpo há muito tempo. Estudaram-no no campo de uma demografia ou de uma patologia históricas; encararam-no como sede de necessidades e de apetites, como lugar de processos fisiológicos e de metabolismos, como alvos de ataques microbianos ou de vírus (...). Mas o corpo também está diretamente mergulhado num campo político; as relações de poder têm alcance imediato sobre ele; elas o investem, o marcam, o dirigem, o supliciam, sujeitam-no a trabalhos, obrigam-no a cerimônias, exigem-the sinais. (....) o corpo só se torna força útil se é ao mesmo tempo corpo produtivo e corpo submisso" (Foucault 1977: 28).

A explosão dos estudos históricos sobre as formas do controle disciplinar, gerindo o corpo do indivíduo e das populações, sobre o discurso médico e o corpo feminino, sobre a construção da maternidade, da prostituição, da vida sexual, etc., foi inevitável. No Brasil, cito, por exemplo, a coletânea organizada por Ronaldo Vainfas (1983) e o estudo de Magali Engels (7 989) sobre o discurso médico e a prostituição no Rio de Janeiro (inicialmente defendido como dissertação de Mestrado, em 1985), ambos produzidos na primeira metade dos anos 80 . Estes estudos vinham fortemente referenciados tanto pelo que se fazia na França ${ }^{2}$, quanto pelos trabalhos pioneiros de Roberto Machado (1978) e Jurandir Freire Costa (1979), respectivamente, enquanto uma historiografia foucaultiana, que problematizava o corpo na História, sem restringir-se à sua dimensão sexual. Na segunda metade dos anos 80 e início dos 90 , vários outros estudos surgiram e continuam a surgir, trazendo importantes informações sobre o corpo feminino e mais recentemente sobre o masculino.

É claro que não se pode caracterizar esta historiografia como de exclusiva inspiração foucaultiana e nem é esse meu objetivo. Certamente, foram e têm sido várias as fontes de inspiração teórica e metodológica destes estudos que, cada vez mais, recusam rótulos e, poderíamos dizer, pensam-se como "anarquistas imaginativos", para usar a atraente expressão que Simon Shama utilizou em entrevista recente. A análise freudiana proposta por Peter Gay, as 
3.Veja-se a respeito Maria Odila Leite da Silva Dias (1994). renovações trazidas pelas diferentes Histórias Culturais, as discussões oriundas dos estudos feministas do gênero, sem dúvida, vêm dinamizar e pluralizar os lugares por onde se lêem e constróem as Histórias do Corpo. Chamo, sim, a atenção para a importância dos estudos de Foucault, enquanto pioneiro, não apenas para se trabalhar a questão da sexualidade enquanto domínio histórico e político, mas enquanto alguém que nos levou a pensar na dimensão do corpo na História, como bem reconheceram os historiadores da Nova História, entre outros. Concordo aqui plenamente com o norte-americano Richard Sennett, que em livro recente, intitulado The flesh and the stone: the body and the city in Western civilization (1994), declara sua imensa divida para com o filósofo francês, com quem muitos anos antes começara a investigar uma história do corpo. Ou então, com a historiadora inglesa Dorinda Outram, que procura integrar a história do corpo com o que denomina de uma história geral, ao se indagar pelo lugar do corpo na Revolução Francesa (Outram 1989). Enfim, os deslocamentos conceituais operados por Foucault, ou a "Revolução Foucaultiana", como quer Paul Veyne, foram fundamentais para que o corpo fosse incorporado como domínio político de conhecimento histórico, desfazendo-se sua antiga e estigmatizada referência.

As feministas e a sexualização do corpo

segundo ponto que, em minha opinião, vale ser destacado nesse debate, refere-se às pressões do movimento feminista sobre a Academia, forçando a incorporação dos temas femininos propriamente ditos, como o corpo, a sexualidade, a saúde da mulher, assim como aqueles pertinentes à esfera da vida privada, pela produção historiográfica. É importante lembrar que até meados dos anos 70, não apenas os temas da historiografia da Revolução eram predominantes - a exemplo da definição e lutas das classes sociais, das formas estritamente políticas da resistência social, do Estado em sua relação com a sociedade civil -, como o próprio discurso histórico, essencialmente masculino, sequer era pensadó enquanto discurso sexualizado.

Ao lado de outros movimentos sociais, o feminismo questionou a figura do sujeito único, branco, racional como universal, apontando para a exclusão das mulheres, assim como dos negros, homossexuais e outros grupos marginalizados. Questionou a narrativa tradicional da História, masculina e pretensamente universalizante, circular em sua lógica identitária e incapaz de pensar as diferenças e multiplicidades. Questionou, ainda, as formas através das quais as questões femininas passavam a ser discutidas e incorporadas, nos anos 70, por uma narrativa masculina pronta e acabada. Nesse sentido, as discussões sobre as contribuições da "epistemologia feminista" vêm certamente ganhando destaque e interesse, não só para os grupos feministas, na atualidade ${ }^{3}$.

A valorização da história do corpo ocorreu, portanto, paralelamente à entrada dos temas da mulher na História e isto se deu também como uma conquista das lutas feministas. Discutir a dominação patriarcal, machista e masculina sobre as mulheres nas diferentes sociedades e momentos históricos significou inevitavelmente falar historicamente da construção do corpo feminino pelo discurso do poder, das leituras impostas sobre as reações, o desejo, os sintomas, as doenças, os ciclos vitais das mulheres e suas estigmatizações misóginas. Implicou falar-se 
da sexualidade feminina enquanto campo de investimento do discurso médico, jurídico e religioso principalmente, e não há dúvida de que esta foi e continua ainda sendo uma das áreas de maior produção historiográfica, em se tratando do corpo. Sem dúvida alguma, até o presente momento acumulamos um conhecimento muito maior a respeito da história do corpo feminino, das teorias, representações, fantasias elaboradas sobre ele, assim como de seus modos de funcionamento clínico, emocional, sexual e psicológico, do que sobre o corpo masculino, muito embora este quadro tenda a se reverter e equilibrar, com os novos estudos sobre as masculinidades.

De certo modo, o interesse pela história do aborto, da maternidade, da prostituição, da virgindade, da menstruação, das formas da sedução, etc., assim como a busca de novas categorias analíticas a partir das quais estes assuntos puderam ser abordados, cresceram proporcionalmente às exigências de esclarecimento teórico e fundamentação política colocados pelas lutas feministas. Em suma, iniciando-se a partir da análise e descrição das formas da dominação política, social, ideológica e sexual sobre o corpo, passou-se, num segundo momento, a se pensar o corpo enquanto espaço da festa, do lúdico, do desejo e da sedução.

É importante lembrar também que ao evidenciar a necessidade de revalorização da "cultura feminina" enquanto direito à diferença, nos anos 80 , 0 feminismo pressionou para a des-hierarquização das esferas pública e privada, deslocando o foco das atenções para o domínio doméstico enquanto campo saturado de significados e representações fundamentais para o conhecimento histórico de determinada sociedade. Propôs, então, não só trazer as mulheres para o discurso histórico, mas contar a "História no feminino". Falar da "cozinha", de repente, tornou-se tanto ou mais importante que referir-se à sala e às ruas.

\section{Os homossexuais e a desconstrução do corpo}

Finalmente, quero destacar o impacto das reivindicações e denúncias trazidas pelos movimentos homossexuais, masculino e feminino, sobre a historiografia contemporânea. Questionando os padrões de masculinidade e de feminilidade vigentes enquanto construções culturais e sociais, denunciando o imperialismo do modelo heterossexual de comportamento sexual, estes movimentos forçaram a incorporação de discussões teóricas e temáticas em que o corpo ganhou destaque. A desnaturalização e "desconstrução" do corpo e do sexo que propuseram significou a necessidade de historização das práticas corporais e sexuais não apenas na contemporaneidade, mas ao longo da História. Datam dos anos 70 os estudos de história das relações homossexuais na Antigüidade, na Grécia Antiga ou em Roma, enquanto o segundo volume da História da sexualidade, de Foucault, focalizando o uso dos prazeres, aparecia em 1984. Fundamental para a discussão políitica e para a luta pelos direitos dos homossexuais, nesse livro, o filósofo mostrava a "invenção da homossexualidade" pelo discurso médico como dispositivo do poder, fá que este conceito não poderia ser utilizado para nomear as relações de amor entre os homens naquele mundo da Antigüidade Clássica. Nesta direção, destaco, ainda, o relativamente recente trabalho do psiquiatra Jurandir Freire Costa, A inocência e o vício (1992), em que partindo 
das discussões sobre a construção cultural e ideológica da homossexualidade a partir de referências médicas, fundadas na partilha entre o normal e o patológico, desde a segunda metade do século passado, propõe o abandono do conceito e sua substituição pelo de "homoerotismo", como forma de luta política para a superação das estigmatizações e perseguições de que têm sido vítimas os homossexuais.

Acredito que podemos contribuir para o balanço e a discussão sobre a produção historiográfica que trabalha com o corpo, em suas diferentes percepções e manifestações culturais, ao considerarmos estes lugares de origem, de inserção da temática, já que por aí se definiram os campos e as maneiras de apreensão dos fenômenos corporais pelos historiadores. Nesse sentido, o corpo emergiu, nos anos 70, sobretudo, como lugar de investimento do "dispositivo da sexualidade", como espaço privilegiado da dominação social e política, para, num segundo momento, ser interrogado em seus múltiplos significados e simbolizações, com o apoio da Psicanálise e da Antropologia, a exemplo do que fez Peter Gay em A educação dos sentidos (1988). 